\title{
Continuity of teaching and assistance activities for breast cancer specialists during the pandemic
}

\author{
Gil Facina ${ }^{1}$
}

Dear friends,

In 2021, the world that had been devastated by the pandemic of the new coronavirus that affected millions of people in all spheres and caused a great socioeconomic impact began to recover with the development of different vaccines for the prevention of coronavirus disease 2019 (COVID-19).

Parallel to this effort by the pharmaceutical industry, doctors committed themselves to the treatment of people affected by this disease, and due to the advance of the pandemic, many patients stopped looking for primary services to perform screening for breast cancer.

It is estimated that in Brazil, there was a decline in mammograms of about $42 \%$, that is, the SUS (Unified Health System) carried out, in 2019, 1.9 million mammograms among patients who aged 50-69 years and performed, in 2020, in the full pandemic, only 1.1 million exams.

Based on this observation, mastologists, together with the Brazilian Society of Mastology, began to guide patients so that they would not stop performing mammographic screening and launched the campaign with the motto The sooner, the better, so that the population becomes aware of the importance of early diagnosis and treatment, in addition to lifestyle changes.

Despite all the difficulties imposed by the pandemic, in April 2021, breast cancer specialists held a great online event, the XXIII Brazilian Congress of Mastology, which was exquisitely organized by the Brazilian Society of Mastology — Regional of Santa Catarina with support from SBM - National.

Countless international and national speakers brightened our event, and dozens of works were presented. The best studies are available in this supplement!

Good reading! 